\title{
Suicide due to fear of COVID-19, in pregnancy, lead to Neonatal malformations: A case report
}

\author{
Javad Boskabadi ${ }^{1}$, Saeed Kargar-Soleiman abad ${ }^{2}$, shahrokh mehrpishe ${ }^{3}$, Elham Pishavar ${ }^{4}$, \\ and Roya Farhadi ${ }^{3}$ \\ ${ }^{1}$ Mazandaran University of Medical Sciences Faculty of Pharmacy \\ ${ }^{2}$ Mazandaran University of Medical Sciences Faculty of Medicine \\ ${ }^{3}$ Mazandaran University of Medical Sciences \\ ${ }^{4}$ Mashhad University of Medical Sciences Faculty of Pharmacy
}

June 15, 2021

\begin{abstract}
There is limited data about various effect of COVID-19 in pregnancy. The Covid-19 pandemic can increase anxiety or schizophrenia exacerbation. Neonatal malformations from antipsychotic drugs exposures during first trimester of pregnancy have been reported. However, their effect near delivery have been less studied. Keywords: Covid-19, pregnancy, mental health, neonatal malformations
\end{abstract}

\section{Introduction}

The Coronavirus Disease 2019 (COVID-19) were first reported in December 2019 in Hubei province, China 1,2 .

All ages and genders are at risk for Covid-19 infection, but there is limited information about various effect of COVID-19 in pregnant women. Pregnant patients often were excluded from the clinical trials and most data about COVID-19 have come from non-pregnant studies. ${ }^{3}$

Studies have shown that, pregnancy is associated with a fear of COVID-19. ${ }^{4}$ The pregnancy period is often accompanied by mental problems especially in women with psychiatric and anxiety disorders. ${ }^{5}$ High stress of Covid-19 pandemic, news of spread, financial stress for people who lost their job, death causes by virus, disruption of treatment and limitation of refer to medical centers can increase mental disorders, all these reasons made development of some new onset psychotic disorders in people without any past mental disorders history and can cause exacerbation of psychotic symptoms of patient with this disease. ${ }^{6}$

Psychotic disorders are reasons for harmful outcomes include: suicide, homicide and other dangerous behaviors. Based on this insight usually suicide rate introduce as a proxy to indicate level of mental health in general population. Generally, $90 \%$ of suicide associated with at least one mental disorder like psychosis or depression. ${ }^{7,8}$,

The pregnant women with mental disease are more subspecies to suicide with their drugs comparing with the general population. ${ }^{9}$ The safety issue of antipsychotic and antidepressants drugs in last month of pregnancy and near delivery has not been established.

\section{Case presentation}

This study was conducted according to the Declaration of Helsinki principles. Also, CARE guidelines and methodology have been followed. A 5 days' new born boy with $3300 \mathrm{~g}$ birth weight with seizure, 
frequent apnea, rise in ammoniac and lactate blood and reveal meconium aspiration as chief complaint was referred from the parturition center to our neonatal intensive care unit (Bu Ali Sina Hospital, Sari, Mazandaran Province, Iran). His mother suffered from schizophrenia, major depression and anxiety disorder that treated with risperidone, quetiapine, sertraline and clonazepam. In COVID-19 quarantine period and fear of infection, she imagines infected with covid-19 and decides to suicide with her medicines, whereas was in the last month of pregnancy and near of delivery. However, she wasn't successful because of immediately medical intervention. She visited an obstetrician /gynecologist for her pregnancy follow up and decided to termination of pregnancy. After delivery, the newborn baby suffered from recurrent seizures and apnea. In pervious center, physician use phenobarbital to treat new born seizure and referred him to us. Primary lab tests including BUN, Cr, blood sugar, calcium, Total bilirubin, Direct bilirubin, K, Na, CRP, arterial blood gas $(\mathrm{ABG})$, were requested. All these tests show normal situation except direct bilirubin and ABG results (Table.1). The increase in direct bilirubin level was attributed to neonatal icterus and frequent apnea can cause ABG abnormality. Patient scheduled for ultrasonography and echocardiography. The results of brain sonography showed $2.7(\mathrm{~mm})$ choroid plexus and an absorbing germinal matrix hemorrhage (Fig.1). Also, in abdominopelvic sonography revealed undescended testis (UDT), unilateral hydronephrosis in left kidney with $7 / 6$ diameter. Nephrologist and endocrinologist consult requested. The echocardiography demonstrates atrial septal defect (ASD), patent ductus arteriosus (PDA), and mild tricuspid regurgitation (TR). MRI results reveal temporoparietal lesion in imaging (Fig.2). After all these examination and evaluation; phenytoin for his seizure, meropenem with amikacin for meconium aspiration and caffeine for apnea were perescripted. Phenytoin prevent seizures and it doesn't repeat again. But five days after phenytoin started, dermatologic side effects including generalized rash, redness and maculopapular lesions were observed. So, phenytoin discontinued and exchanged to levetiracetam syrup $0.5 \mathrm{ml}$ twice per day. Dermatologic consult was requested and topical Hydrocortison and Eucerin was prescribed. This treatment was useful and rashes vanished in next five days. Endocrine evaluation demonstrated no pathology, and total T4, free T4, TSH and blood sugar were in normal range. Eventually, after two weeks, patient was discharged from hospital and scheduled for refer to neurology, nephrology and cardiac clinic for treat his defects and follow up. In follow up checkup and evaluation of patient after five months, left upper limb was accompanied with little paresthesia with no more adverse effect.

\section{Discussion}

Depressive and anxiety disorders are more common in women than men (1.5-2.5 times), whereas schizophrenia was shown greater in men ${ }^{10}$. Childbirth and pregnancy are introduced as major emotional, physical and social events in woman's life; level of hormones in blood and its change is one of the reasons proposed for change in mental health of woman in pregnancy period; so it's possible for woman to queer to mental disorders like depression . ${ }^{11,12}$

Studies show that covid-19 pandemic lead to increase levels of anxiety, depression, stress, and alcohol use. ${ }^{13,14}$ Women with schizophrenia face a range of adverse pregnancy outcomes including pre-eclampsia, thromboembolic disease, preterm birth and alterations in fetal growth in compression with the general population ${ }^{15}$. Recent finding suggests no clinically considerable raise in congenital malformations among offspring of women taking first- or second-generation antipsychotics in pregnancy. Respiratory distress reported in neonates who were exposed to antipsychotic drugs. However, careful evaluation has not carried out on relative risk of antipsychotics drugs fetal growth ${ }^{16}$. For example, rispeirdone from benzisoxazole derivatives is atypical antipsychotics that first developed 1990s. Although, its safety during pregnancy has not been established. Among different studies, only two reported case recognized major organ malformations as consequences of rispeirdone, and four cases reported perinatal syndromes (two premature births, one case of a nuchal umbilical cord and a case of a behavioral disorder $)^{17}$.

Neonatal malformations from quetiapine exposures during first trimester of pregnancy have been reported. In animal studies sertraline lead to impaired growth of the heart. However, meaningful risk and delivery outcomes following sertraline exposure in human researches, have not been reported. ${ }^{18}$ No evidence for an increase in congenital malformations in new born exposed to benzodiazepines such as clonazepam during the 
first trimester of pregnancy. ${ }^{19}$ But its effect near delivery is unclear.

Most studies related to drug safety in pregnancy have focused on the long-term effects and therapeutic doses specifically in first trimester of pregnancy. The effects of high doses of drugs and suicide with multi drugs near the delivery have been less studied

This unsuccessful suicide demonstrates common psychiatric treatment for patient may has enough promising effect; but in pandemic period can't be useful. This situation has huge impact on mental health, so it shows need for intensive care for patient with psychiatric disorder.

\section{Conclusion}

Currently covid-19 has great influence on mental health and it changes our life. The safety of some antipsychotic and antidepressants drugs in the last month of pregnancy and near delivery has not been clearly investigated. Neonatal malformations due to risperidone and quetiapine exposures, creates doubts in using these antipsychotic drugs during pregnancy.

\section{Disclosure Statement}

The authors have no conflicts of interest to declare.

\section{Funding Sources}

This research received no external funding.

\section{Author contributions}

J. B, and S.K , Data curation, Writing- Original draft preparation, SH. M and E.P Reviewing and Editing,R.F Supervision.

\section{Information Consent}

Information consent for publication were gave verbally (Newborn from his father and young mother form her legal guardians).

\section{Availability of data}

The data are available from the corresponding author on reasonable request.

\section{ORCID ID}

Javad Boskabadi: https://orcid.org/0000-0001-9186-5445

Saeed Kargar Soleiman-abad: https://orcid.org/0000-0001-5602-3816

Elham Pishavar: https://orcid.org/0000-0002-3951-0484

Roya Farhadi: https://orcid.org/0000-0002-6525-527X

\section{References}

1. Zaigham M, Andersson O. Maternal and perinatal outcomes with COVID-19: A systematic review of 108 pregnancies. Acta Obstet Gynecol Scand . Jul 2020;99(7):823-829. doi:10.1111/aogs.13867

2. Ahn DG, Shin HJ, Kim MH, et al. Current Status of Epidemiology, Diagnosis, Therapeutics, and Vaccines for Novel Coronavirus Disease 2019 (COVID-19). J Microbiol Biotechnol . Mar 28 2020;30(3):313324. doi:10.4014/jmb.2003.03011

3. Rasmussen SA, Smulian JC, Lednicky JA, Wen TS, Jamieson DJ. Coronavirus disease 2019 (COVID-19) and pregnancy: what obstetricians need to know. Am J Obstet Gynecol . 2020;222(5):415-426.

4. Corbett GA, Milne SJ, Hehir MP, Lindow SW, O'connell MP. Health anxiety and behavioural changes of pregnant women during the COVID-19 pandemic. Eur J Obstet Gynecol Reprod Biol . 2020;249:96. 
5. Salehi L, Rahimzadeh M, Molaei E, Zaheri H, Esmaelzadeh-Saeieh S. The relationship among fear and anxiety of COVID-19, pregnancy experience, and mental health disorder in pregnant women: A structural equation model. Brain and behavior. 2020;10(11):e01835.

6. Rentero D, Juanes A, Losada CP, et al. New-onset psychosis in COVID-19 pandemic: a case series in Madrid. Psychiatry Res . Aug 2020;290:113097. doi:10.1016/j.psychres.2020.113097

7. Mamun MA, Griffiths MD. First COVID-19 suicide case in Bangladesh due to fear of COVID19 and xenophobia: Possible suicide prevention strategies. Asian J Psychiatr. Jun 2020;51:102073. doi:10.1016/j.ajp.2020.102073

8. Taylor PJ, Kalebic N. Psychosis and homicide. Curr Opin Psychiatry . May 2018;31(3):223-230. doi:10.1097/yco.0000000000000411

9. de Vries B, van Busschbach JT, van der Stouwe ECD, et al. Prevalence Rate and Risk Factors of Victimization in Adult Patients With a Psychotic Disorder: A Systematic Review and Meta-analysis.Schizophrenia bulletin. Jan 1 2019;45(1):114-126. doi:10.1093/schbul/sby020

10. Cantwell R. Mental disorder in pregnancy and the early postpartum.Anaesthesia . 2021;76:76-83.

11. Raza SK, Raza S. Postpartum Psychosis. StatPearls . StatPearls Publishing Copyright (C) 2020, StatPearls Publishing LLC.; 2020.

12. Friedman SH, Hall RCW, Sorrentino RM. Involuntary Treatment of Psychosis in Pregnancy. J Am Acad Psychiatry Law . Jun 2018;46(2):217-223. doi:10.29158/jaapl.003759-18

13. Ferrando SJ, Klepacz L, Lynch S, et al. COVID-19 Psychosis: A Potential New Neuropsychiatric Condition Triggered by Novel Coronavirus Infection and the Inflammatory Response? Psychosomatics . May 19 2020;doi:10.1016/j.psym.2020.05.012

14. de Burgos-Berdud I, Valdés-Florido MJ, López-Díaz Á. Are healthcare workers during the COVID19 pandemic at risk of psychosis? Findings from a scoping review. Gen Hosp Psychiatry . Jul 2 2020;doi:10.1016/j.genhosppsych.2020.06.015

15. McAllister-Williams RH, Baldwin DS, Cantwell R, et al. British Association for Psychopharmacology consensus guidance on the use of psychotropic medication preconception, in pregnancy and postpartum 2017.J Psychopharmacol . 2017;31(5):519-552.

16. Vigod SN, Gomes T, Wilton AS, Taylor VH, Ray JG. Antipsychotic drug use in pregnancy: high dimensional, propensity matched, population based cohort study. $b m j$. 2015;350

17. Coppola D, Russo LJ, Kwarta RF, Varughese R, Schmider J. Evaluating the postmarketing experience of risperidone use during pregnancy.Drug Saf . 2007;30(3):247-264.

18. Damkier P, Videbech P. The safety of second-generation antipsychotics during pregnancy: a clinically focused review. CNS drugs . 2018;32(4):351-366.

19. Creeley CE, Denton LK. Use of Prescribed Psychotropics during Pregnancy: A Systematic Review of Pregnancy, Neonatal, and Childhood Outcomes. Brain Sci . 2019;9(9):235.

Table.1 . Newborn Laboratory data after NICU admission

\begin{tabular}{ll}
\hline negative & Blood culture \\
\hline negative & Coombs test direct \\
$1.2 \%$ & Reticulocyte \\
$20 \mathrm{U} / \mathrm{g} \mathrm{Hb}$ & G.6.P.D \\
$9000 / \mathrm{mm}^{3}$ & WBC \\
$45.3 \%$ & HCT
\end{tabular}




\begin{tabular}{|c|c|}
\hline negative & Blood culture \\
\hline $225000 / \mathrm{mm}^{3}$ & PLT \\
\hline $16.2 \mathrm{~g} / \mathrm{dl}$ & $\mathrm{HgB}$ \\
\hline $116 \mathrm{mg} / \mathrm{dl}$ & Blood sugar \\
\hline 18 mg/dl & Urea \\
\hline $0.6 \mathrm{mg} / \mathrm{dl}$ & Creatinine \\
\hline $8.4 \mathrm{mg} / \mathrm{dl}$ & Calcium \\
\hline $11 \mathrm{mg} / \mathrm{dl}$ & Bil.T \\
\hline $0.9 \mathrm{mg} / \mathrm{dl}$ & Bil.D \\
\hline 4.1mEq/L & K \\
\hline $137 \mathrm{mEq} / \mathrm{L}$ & $\mathrm{Na}$ \\
\hline $3 \mathrm{mg} / \mathrm{L}$ & C.R.P \\
\hline $14 \mathrm{mmol} / \mathrm{L}$ & Lactate \\
\hline $189 \mu / \mathrm{dL}$ & Ammonia \\
\hline $1.8 \mathrm{mIU} / \mathrm{L}$. & TSH \\
\hline $6.3 \mu \mathrm{g} / \mathrm{dL}$ & T4 Total Thyroxin \\
\hline $14.2 \mathrm{ng} / \mathrm{dL}$ & Free $\mathrm{T} 4$ \\
\hline 7.341 & $\mathrm{pH}$ \\
\hline $34.9 \mathrm{mmHg}$ & $\mathrm{pCO}_{2}$ \\
\hline$-6.3 \mathrm{mmol} / \mathrm{L}$ & Base excess \\
\hline $18.5 \mathrm{mmol} / \mathrm{L}$ & $\mathrm{HCO}_{3}$ \\
\hline
\end{tabular}

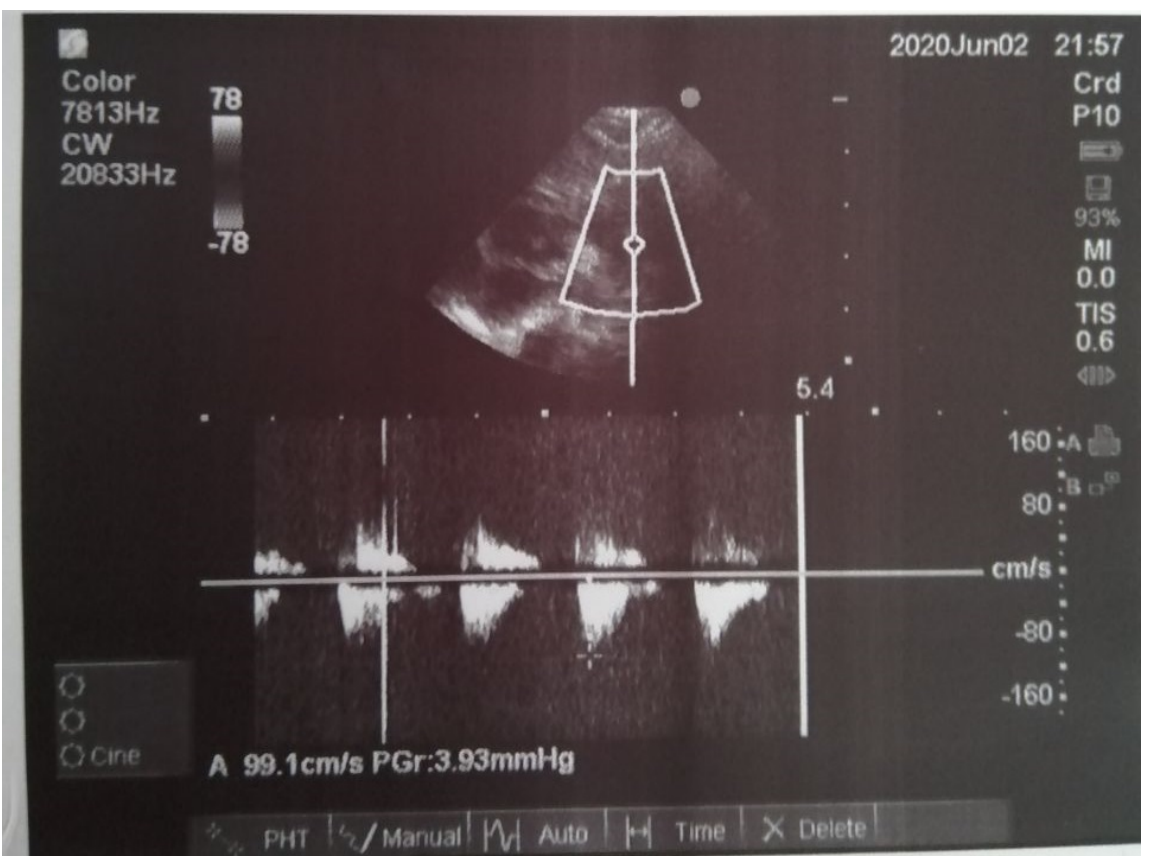

Fig 1. Ultrasonography result of brain showed choroid plexus $2.7(\mathrm{~mm})$ 

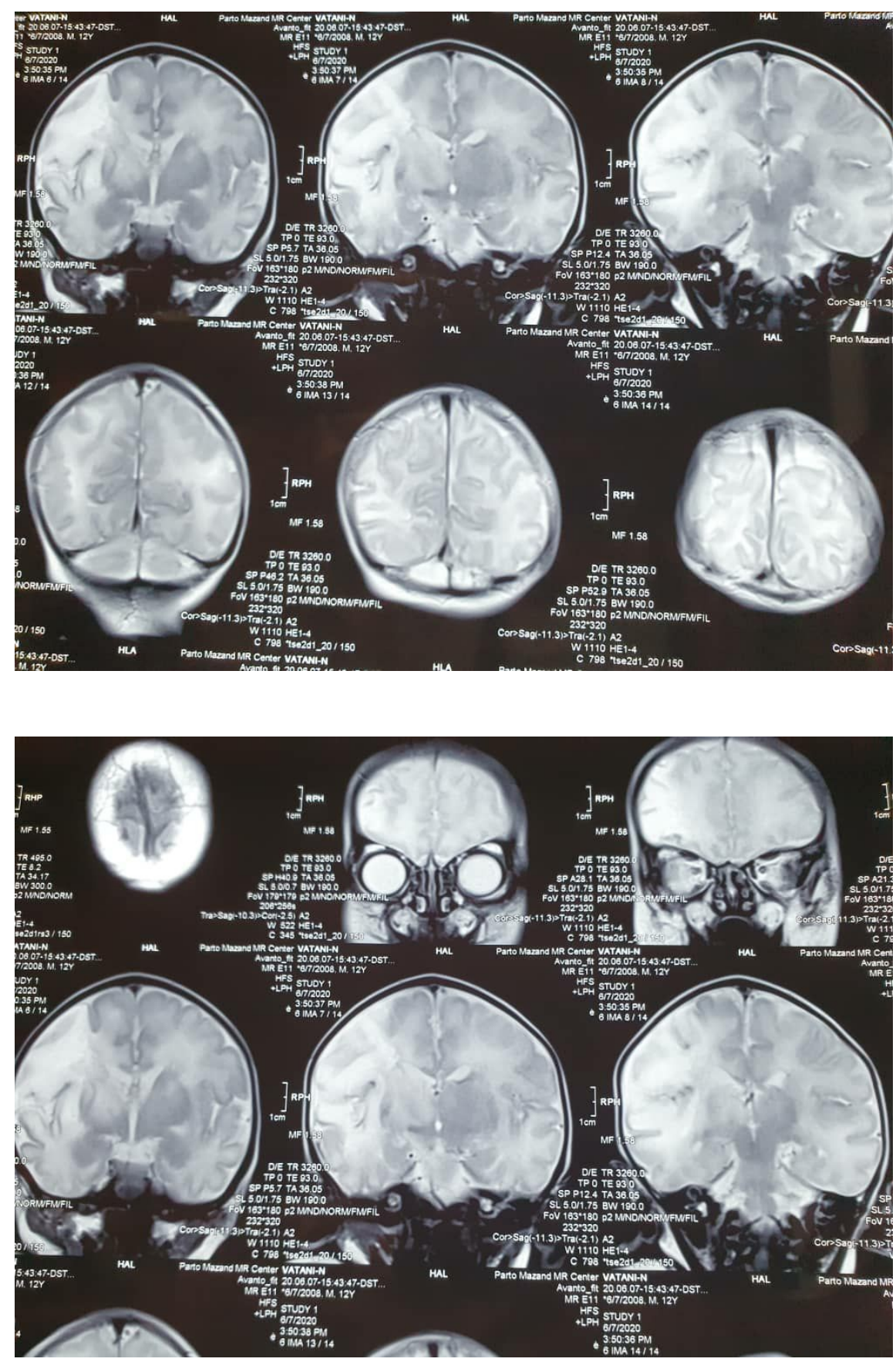

Hosted file

Figures.docx available at https://authorea.com/users/419846/articles/526229-suicide-due-tofear-of-covid-19-in-pregnancy-lead-to-neonatal-malformations-a-case-report 